IBAD Sosyal Bilimler Dergisi

IBAD Journal of Social Sciences

dergipark.org.tr/ibad

IBAD, 2021; (11): 77-92

DOI: $10.21733 /$ ibad.909327

Özgün Araştırma / Original Article

\title{
Sualtı Kültür Mirası Araştırmaları Hakkında Bibliyometrik Bir Analiz
}

\section{A Bibliometric Analysis About The Underwater Cultural Heritage Research}

\author{
Şimal Ertek ${ }^{*}$ \\ Mehmet Tahsin Şahin²

\section{* Sorumlu yazar \\ Corresponding author} \\ ${ }^{1}$ Akdeniz Üniversitesi, Türkiye \\ Akdeniz University, Turkey \\ simalertek1@gmail.com \\ ORCID ID 0000-0001-7555-8883
}

2 Dr. Öğr. Üyesi, Akdeniz Üniversitesi, Türkiye Assist. Prof. Dr., Akdeniz University, Turkey, tahsinsahinakdeniz.edu.tr

ORCID ID 0000-0003-1012-6814

Makale geliş tarihi / First received : 04.04.2021

Makale kabul tarihi / Accepted : : 11.05.2021

Bilgilendirme / Acknowledgement:

Yazarlar aşağıdaki billgilendirmeleri yapmaktadırlar:

1- Araştırma birinci yazarın seminer çalışmasından türetilmiş ve ikinci yazarın danışmanlığında gerçekleştirilmiştir.

2- Bu makalede araştırma ve yayın etiğine uyulmuştur.

3- Araştırmada etik kurul izni alınması gerektiren bir durum yoktur.

4. Yazarlar arasında çıkar çatışması bulunmamaktadır.

5. Araştırmacıların katkı oranı eşittir.

This article was checked by Turnitin. Similarity Index 5\%

\section{Atıf bilgisi / Citation:}

Ertek, Ş., Şahin, M.T. (2021). Sualtı kültür mirası araştırmaları hakkında bibliyometrik bir analiz. IBAD Sosyal Bilimler Dergisi, (11), 77-92. 
ÖZ

Arkeolojik miras, insanlık tarihindeki etkileşimlerin belgeleri olarak görülmektedir. Bu belgelerin ortaya çıkarılıp araştırılması, korunması ve doğru bir biçimde yönetilmesi gerekmektedir. Sualtı kültür mirasının korunması ve anlaşılması, iklim, deniz seviyesi ve kültürel değişimlerin anlaşılmasını aynı zamanda gelecek nesillere aktarılmasını sağlamaktadır. Bu sebeple Sualtı Kültür Mirası alanında yapılan çalışmalar önem arz etmektedir. Yapılan literatür taramaları sonucunda Sualtı Kültür Mirası Araştırmaları konusunda herhangi bir bibliyometrik analiz çalışmasına rastlanılmamaktadır. Bu bakımdan bu çalışma önem arz etmektedir. Bu araştırmada, Sualtı Kültür Mirası Araştırmaları hakkında yayınlanmış olan araştırmalar incelenmektedir. Veri tabanı olarak Taylor and Francis, ScienceDirect, Web of Science, DergiPark, Sobiad, Tr Dizin (Ulakbim) seçilmiştir. Tüm veri tabanlarında yapilan taramalar sonucunda 1976-2020 yılları arasında çalışılmış olan 250 makale incelemeye alınmıştır. Makaleler incelenirken nitel araştırma yöntemlerinden bibliyometrik analiz tekniği kullanılmıştır. Araştırma kapsamındaki makaleler belirlenen kategorilerde sayısallaştırılıp grafiklere dönüştürülerek yorumlanmıştır.

\section{Anahtar kelimeler}

Sualtı Arkeolojisi, Sualtı Kültür Mirası, Bibliyometrik Analiz

\section{ABSTRACT}

Archeological heritage is regarded as documents of interactions in human history. These documents need to be discovered, investigated, protected and managed correctly. The protection and understanding of underwater cultural heritage also ensure that climate, sea level, and cultural changes are understood and communicated to future generations. For this reason, studies in the field of Underwater Cultural Heritage are important. As a result of the literature reviews, there is no bibliometric analysis study on Underwater Cultural Heritage Researches. In this point of view, this study is important. This research examines the published research on Underwater Cultural Heritage Studies. Taylor and Francis, ScienceDirect, Web of Science, DergiPark, Sobiad, Tr Dizin (Ulakbim) has been selected as the database. The results of scans in all databases were reviewed in 250 articles that were worked between 1976-2020. Bibliometric analysis technique was used in qualitative research methods when reviewing articles. Articles in the research have been interpreted by digitizing and converting them into graphs in selected categories.

\section{Keywords}

Underwater Archaeology, Underwater Cultural Heritage, Bibliometric Analysis 


\section{GíRIŞ}

Geçmişten günümüze insan ve insan topluluklarının kökenleri, gelişimleri hakkında bilgi edinilmesi ve o bilgilerin yorumlanması bu toplulukları tanımak için oldukça önemlidir. Arkeolojik miras, insanlık tarihindeki etkileşimlerin belgeleri olarak görülmektedir. $\mathrm{Bu}$ belgelerin ortaya çıkarılıp araştırılması, korunması ve doğru bir biçimde yönetilmesi gerekmektedir (ICOMOS, 1990, s. 1).Arkeolojik miras sadece karada değil su altında da bulunmaktadır. Su altında yer alan bu arkeolojik miraslar Sualtı Kültür Mirası olarak tanımlanmaktadır. UNESCO (United Nations Educational, Scientific and Cultural Organization) tarafından, Sualtı Kültür Mirası'nın korunması alanında 2001 yılında uluslararası bir sözleşme oluşturulmuştur. Bu sözleşmede; " "Sualtı Kültür Mirası” en az yüz yıldır kısmen ya da tamamen, periyodik ya da sürekli olarak su altında bulunan; kültürel, tarihi ya da arkeolojik mahiyeti olan insan kalıntıları anlamına gelmektedir." şeklinde tanımlanmıştır (UNESCO, 2001, s. 2).

Sualtı kültür mirasının korunması ve anlaşılması, iklim, deniz seviyesi ve kültürel değişimlerin anlaşılmasını aynı zamanda gelecek nesillere aktarılmasını sağlamaktadır (UNESCO, 2018, s. 3). Bu sebeple Sualtı Kültür Mirası alanında yapılan çalışmalar önem arz etmektedir. Yapılan literatür taramaları sonucunda Sualtı Kültür Mirası Araştırmaları konusunda herhangi bir bibliyometrik analiz çalışmasına rastlanılmamaktadır. Bu bakımdan bu çalışma önem arz etmektedir.

Sualtı kültür mirası araştırmaları konusunda yapılan bu bibliyometrik analiz çalışması ile alanda çalışma yapmak isteyenlere, daha önce yapılmış olan çalışmaların niteliklerinin gösterilmesi ve eksik olan alanlar konusunda farkındalık oluşturarak literatüre katkı sağlaması amaçlanmaktadır.

Sualtı Kültür Mirası Araştırmaları alanında yapılan bu çalışmanın içeriğinde öncelikle Arkeolojik Miras, Sualtı Kültür Mirası tanımlamaları yapılacaktır. Ardından Sualtı Arkeolojisi'nin tarihinden kısaca bahsedilecek olup, bir sonraki bölümde çalışmada kullanılan veri ve yöntem ele alınacaktır. Son bölümde ise elde edilen bulgular yorumlanarak tartışılacaktır.

\section{SUALTI KÜLTÜR MİRASI TARİHI}

Ülkemizde genel olarak Sualtı Arkeolojisi olarak tanımlanan bu disiplin aslında bünyesinde Deniz Arkeolojisi, Kıyı Şeridi Arkeolojisi, Nehir Arkeolojisi, Sulak Alan Arkeolojisi, Kıyı ve Ada Arkeolojisi, Derin Su Arkeolojisi, Göl Arkeolojisi gibi alt disiplinleri barındırmaktadır. Alt disiplinlerin tamamı çalıştıkları farklı fiziki alanlardan dolayı farklı isimlerle tanımlanmıştır (Özdoğan, 2011, s. 152-154).

İlk olarak sualtındaki eserlerin çıkarılması hazine avcıllğı veya antikacılık düşüncesi ile yapılmıştır (Gölbaş, 2019, s. 589). 19. yüzyılın ortalarında çok sayıda su altı keşfi arkeolojik araştırmalara yeni bir yön vermiştir. 1853-1854 yıllarında İsviçre göllerinin seviyesinin kuraklık nedeniyle düşmesi ile ortaya çıkan ahşap direklerin bulunduğu alanın primitif tekniklerle kazılması ve belgelenmesi bu çalışmaların ilk örneğini oluşturmaktadır. Yapılan bütün bu çalışmalar tatlı su sahalarında yapılmış olup Sualtı Arkeolojisi'nin denizden uzak bir su ortamında doğduğunu göstermektedir (Blot, 1996, s. 24-25). Dünya'da 1904 yılında Meksika'da bulunan "Chichen Itza" tapınağının yanındaki obrukta, ilk defa bir arkeoloğun dalış yaparak 
arkeolojik eserleri incelediği bilinmektedir. Türkiye' de ise dalış eğitimi almış olan bir arkeolog tarafından yapılan ilk bilimsel sistematik sualtı kazısı 1960 yılında Gelidonya Batığı'nda George Bass tarafından gerçekleştirilmiştir (Gölbaş, 2019, s. 590). George Bass' in çalışmaları ile aynı zamanda batık arkeolojisi kapsamında yapılan kazılarda kullanılan metodoloji belirlenmiştir. (Özdoğan, 2011, s. 154). Bu alanın dünyadaki öncüleri, George Bass ve Cemal Pulak tarafından çalışılmış birçok batık kazısı bulunmaktadır. Gelidonya Batığı ve Girne Batığında sadece George Bass çalışırken, Uluburun Batı̆̆ı, Serçe Limanı Batığı ve Yassıada Batıklarında Cemal Pulak ile birlikte çalışmıştır. Özellikle Türkiye'de ve diğer ülkelerde son yıllarda yapılan çalışmalar ile sualtı arkeolojisi alanında bir artış gözlemlenmektedir (Allotta et al., 2015; Aygün Özkan, 2019; Bruno et al., 2019; Jaklič et al., 2015; Jing \& Li, 2019; Lin, 2020; Lu \& Zhou, 2016; Nornes et al., 2015; Öniz \& Karademir, 2018; Öniz, 2019; Reggiannini \& Salvetti, 2017; Richards et al., 2016; Tuğcu, 2017; Underwood \& Manders, 2019).

\section{VERİ VE YÖNTEM}

Yürütülen bir araştırma sırasında sonuca ulaşabilmek için bir dayanak bilgi, belge ya da ipuçları olarak değerlendirilen bilgiler olmalıdır. Bu bilgilere ulaşma aşaması veri toplama olarak adlandırılmaktadır (Tusside TÜBİTAK, 2020). Veri toplama aracı olarak kullanılan yöntemlerden biri ise doküman taramasıdır. Doküman taraması, basılmış durumda veya çevrimiçi ortamda paylaşılmış olan belgelerin incelenmesi ve değerlendirilmesi için uygulanan bir yöntemdir (Bowen, 2009, s. 27). Döküman taraması ise kendi içerisinde farklı analiz biçimlerini barındırmaktadır. Bunlardan bir tanesi bibliyometrik analizdir. Pritchard bibliyometrinin yani istatistiksel bibliyografyanın tanımını 1969 yılında yayınlanan "Statistical Bibliography or Bibliometrics" adlı makalesinde, "Yazılı iletişim süreçlerine ve yazılı iletişimin çeşitli yönlerini sayıp analiz ederek bir disiplinin doğası ve gelişim sürecine 1şık tutmak" olarak tanımlamaktadır (Pritchard, 1969, s. 348). Bilimsel yayınların aktifliklerini belirlemek amacı ile yapılan bibliyometrik analiz, yapılacağı alana ait yayınların ve tüm çalışmaların belirli niteliklerinin alınarak verilerin işlenebileceği ve sayısallaştıılabileceği, excel gibi programlarda grafiklere ya da tablolara dönüştürülerek yapılan bir nitel araştırma biçimidir. Girilen tüm veriler incelenerek belirli parametreler çerçevesinde araştırma yapılmaktadır. Örneğin, bibliyometrik analiz çalışmaları ile bir alanda yazılmış olan tüm makaleler incelenerek en çok hangi yazarın yayın yaptığı, yapılan bu çalışmalarda en fazla hangi yöntemin kullanıldığı gibi sorular cevaplanabilmektedir (Hotamışlı ve Efe, 2015, s. 103).

Türkiye'de bibliyometrik analiz olarak adlandırılabilecek ilk çalışma Ahmet Kemal Özinönü'nün 1970 yılında yazmış olduğu, Türkiye'nin astronomi, fizik, kimya, matematik, biyoloji ve yer bilimleri alanındaki gelişimini ve durumunu incelemek üzere yaptığı çalışmadır (Al, 2008, s. 10).

Bibliyometrik analiz çalışması yapılırken öncelikle araştırılacak veri tabanları belirlenmiştir. Bilimsel açıdan güvenirlilik sağlayan Akdeniz Üniversitesi Kütüphanesi'nin anlaşmalı olduğu akademik çalışmaların yayınlandığı 6 veri tabanı, Taylor and Francis, ScienceDirect, Web of Science, DergiPark, Sobiad, Tr Dizin (Ulakbim) seçilmiştir. Veri tabanları incelenirken doküman olarak sadece araştırma makaleleri incelenmiştir. Kullanılan veri tabanlarından Taylor and Francis, ScienceDirect ve Web of Science içerisinde Sualtı Kültür Mirası ile ilişkilendirilebilen protection of the underwater cultural heritage (sualtı kültür mirasının korunması), underwater archaeology (sualtı arkeolojisi), submerged (batık), underwater cultural heritage research (sualtı kültür mirası araştırmaları) anahtar kelimeleri kullanılarak tarama yapılmıştır. DergiPark, 
Sobiad, Tr Dizin (Ulakbim) veri tabanlarında ise sualtı kültür mirasının korunması, sualtı arkeolojisi, batık, sualtı kültür mirası araştırmaları anahtar kelimeleri ile tarama yapılmıştır. Bu tarama sonucunda kriterlere uygun olarak analiz yapılacak 250 tane araştırma makalesi tespit edilmiştir. Tespit edilen araştırma makaleleri aşağıda maddeler halinde belirtilen kriterlere uygun olarak sınıflandırılmış olup işlemselleştirilmiştir.

Tablo 1. Bibliyometrik Analiz Kriterleri

\begin{tabular}{|c|c|c|}
\hline K1 & Makalelerin yayınlandığı yıllara göre dağılımı & $\begin{array}{lr}\text { Makalelerin yayınlandı̆̆ } 1 \\
\text { yılların belirlenmesi Sualtı } \\
\text { Kültür } & \text { Mirası } \\
\text { Araştırmalarının } & \text { yıllar } \\
\text { içerisindeki gelişiminin } \\
\text { görülmesi açısından önem } \\
\text { arz etmektedir. }\end{array}$ \\
\hline $\mathrm{K} 2$ & Makalelerin çok yazarlılık açısından durumu & $\begin{array}{l}\text { Yazar sayılarının incelenmesi } \\
\text { çalışmaların niteliklerinin } \\
\text { belirlenmesi açısından } \\
\text { gerekli görülmüştür. }\end{array}$ \\
\hline K3 & Yazarlarının çalıştığı kurumlara göre dağılımı & $\begin{array}{l}\text { Yazarların bağlı oldukları } \\
\text { kurumların } \\
\text { yazarların nitelikleri } \\
\text { belirtmektedir. Bu sebeple bu } \\
\text { araştırmaya kurum bilgisi } \\
\text { eklenmiştir. }\end{array}$ \\
\hline K4 & En sık kullanılan anahtar kelimeler & $\begin{array}{l}\text { Anahtar kelimeler analizin } \\
\text { başlıca kriterlerinden biridir. } \\
\text { Bulunan makaleler anahtar } \\
\text { kelime analizleri ile de } \\
\text { incelenerek arşivlenmiştir. } \\
\text { Makale içeriğini en net } \\
\text { şekilde belli eden öğelerden } \\
\text { biri olduğu için bu } \\
\text { araştırmanın kriterleri } \\
\text { arasında yer almaktadır. }\end{array}$ \\
\hline K5 & En çok yayın yapan 5 ülkenin oransal dağılımı & $\begin{array}{l}\text { Bu kriter, Sualtı Kültür Mirası } \\
\text { Araştırmaları alanında } \\
\text { yazılmış ve analiz } \\
\text { kapsamında incelenmekte } \\
\text { olan araştırmaların hangi } \\
\text { ülkelerden olduğu ve dünya } \\
\text { çapında öne çıkan ülkelerin }\end{array}$ \\
\hline
\end{tabular}




\begin{tabular}{|c|c|c|}
\hline & & $\begin{array}{l}\text { bilgisine ulaşmak amaçl1 } \\
\text { oluşturulmuştur. }\end{array}$ \\
\hline K6 & Yazarların uzmanlık alanlarına göre dağılımı & $\begin{array}{l}\text { Pek çok farklı alandan } \\
\text { yazarların birlikte yaptığ1 } \\
\text { çalışmalar bulunmaktadır. } \\
\text { Bu yazarların en fazla hangi } \\
\text { uzmanlık alanından } \\
\text { oldukları araştırmaların } \\
\text { ortak çalıştığ1 diğer bilim } \\
\text { dallarını yansıtmaktadır. }\end{array}$ \\
\hline K7 & $\begin{array}{l}\text { Bu çalışma kapsamında "Sualtı Kültür Mirası" } \\
\text { hakkında en çok yayın yapan dergiler }\end{array}$ & $\begin{array}{l}\text { "Sualtı Kültür Mirası } \\
\text { Araştırmaları" ile ilgili en } \\
\text { fazla yayın yapan dergilerin } \\
\text { tespiti ileride yayın yapacak } \\
\text { olan araştırmacıların tercih } \\
\text { etmesi ve bilgilenmesi } \\
\text { açısından } \\
\text { bulunmaktadır. }\end{array}$ \\
\hline K8 & $\begin{array}{l}\text { Makalelerin yayınlandı̆̆ı dergiler arasında arkeolojik } \\
\text { dergilerin yüzdesel olarak payı }\end{array}$ & $\begin{array}{l}\text { Bu alanda yapılan çalışmalar } \\
\text { sadece arkeoloji dergilerinde } \\
\text { yayınlanmamaktadır. Birçok } \\
\text { disiplinin çalışma alanı olan } \\
\text { Arkeolojinin hangi disiplinler } \\
\text { ile bağlantılı olduğu ve bu } \\
\text { disiplinlerin dergilerinde ne } \\
\text { derece yayınlandığını } \\
\text { öğrenmek bu analiz } \\
\text { kapsamında } \\
\text { incelenmektedir. }\end{array}$ \\
\hline
\end{tabular}

\section{BULGULAR}

Bu bölümde çalışma kapsamında ele alınan 250 araştırma makalesinin yapılan analiz sonuçları yer almaktadır. Bu analiz sonucunda ortaya çıkan sonuçlar tablo ve grafiklerle detaylandırılmıştır. 


\section{K.1. Makalelerin Yayınlandığı Yıllara Göre Dağılımı}

Şekil 1. Makalelerin Yayınlandı̆̆ı Yıllara Göre Dă̆ılımı

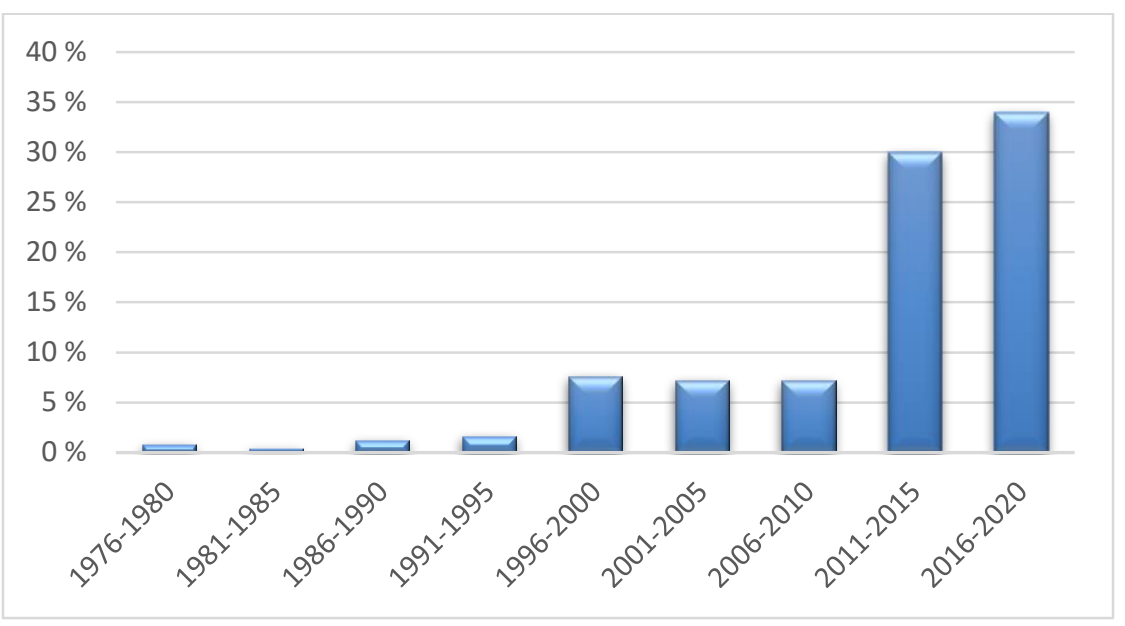

Bu analiz K1' de vurgulanan araştırma makalelerinin yıllara göre dağılımını ortaya koymaktadır. Yillar boyunca bu süreçte oluşan değişimi görmek için 5'er yıllık periyotlarda 9 sinıf oluşturulmuştur. Elde edilen verilere göre ilk sualtı kültür mirası araştırma makalesinin 1976 yılında yayınlandığı görülmektedir. 1976-1980 yılları arasında \%0,8 oranında yayın yapıldığı, 1981-1985 aralığında \%0,4 oranı ile 1976-2020 yılları arasında en düşük paya sahip yıl aralığı olduğu görülmektedir. 1986-1990 yılları arasında \%1,2'lik bir oranda yayınlarda yavaş bir artış görülmektedir. 1996-2000 yılları arasında araştırma makalelerinin arttığı ve \%7 oranlarında (1996-2000 arasında \%7,6, 2001-2005 arasında 7,2, 2006-2010 arasında \%7,2) 2010 yılına kadar yayınlandığı görülmektedir. 2011 yılında araştırma makalelerinde hızla bir artış yaşanmıştır. 9. periyotta yani 2016-2020 arasında bu artış devam etmiştir (Şekil 1).

\section{K.2. Makalelerin Çok Yazarlılık Açısından Durumu}

Şekil 2. Makalelerin Çok Yazarlılık Açısından Durumu

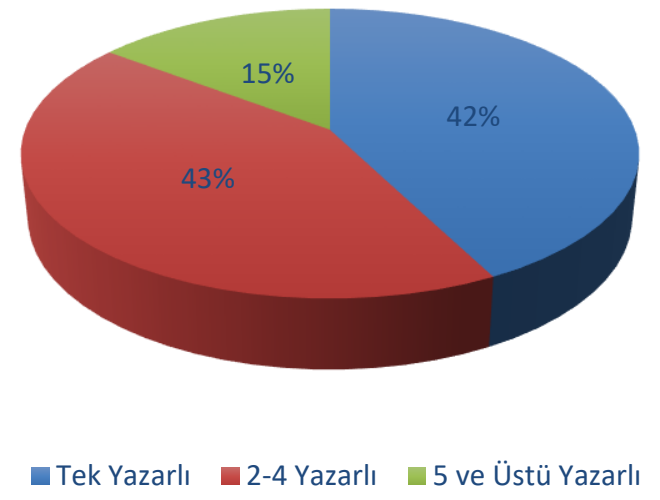

Analiz kapsamında incelenen 250 makale içerisinde K2 kriterinde belirtilen çok yazarlılık açısından inceleme işlemi gerçekleştirilmiş olup, bu bölümde detaylandırılmıştır. Tek yazarlı makaleler tüm makaleler içerisinde $\% 42$ lik bir alanı kaplamaktadır. İncelenen makaleler arasında 2-4 yazarlı olan 108 çalışma görülmekte ve bu çalışmalar tüm makaleler içerisinde \%43 oranındadır. 5 ve üstü yazarlı makaleler incelendiğinde en fazla 10, 22 ve 31 yazarlı makaleler 
olduğu ve bu araştırmaların tüm makaleler içerisinde \%15 paya sahip olduğu görülmektedir. (Şekil 2).

\section{K.3. Yazarlarının Çalıştı̆̆ı Kurumlara Göre Dağılımı}

Şekil 3. Makalelerin Yazarlarının Çalıştı̆̆g Kurumlara Göre Dağılımı

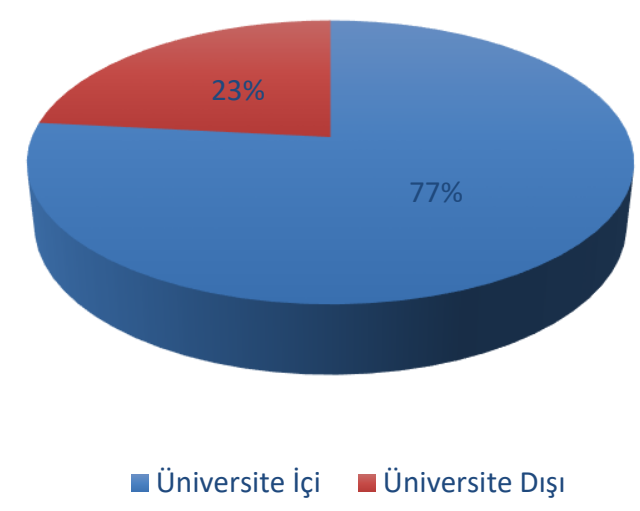

Bu bölümde analiz kapsamında incelenen tüm makaleler içerisinde K3 kriterinde belirtildiği gibi makalelerin yazarlarının bağlı olduğu kurum bilgilerine ulaşılarak bu bilgilerin sayısallaştırma işlemi yapılmıştır. Araştırmaların yazarlarına ait toplamda 635 kurum bilgisine ulaşılmıştır. $\mathrm{Bu}$ bilgiler üzerinden yazarların kurumları incelendiğinde en büyük payda ile \%77'sinin üniversitelere bağlı olduğu görülmekte aynı zamanda \%23'lük bir kesimin üniversite dışı kurumlardan (özel şirketler gibi) olduğu görülmektedir (Şekil 3).

\section{K.4. En Sik Kullanılan Anahtar Kelimeler}

Şekil 4. En Sık Kullanılan Anahtar Kelimeler

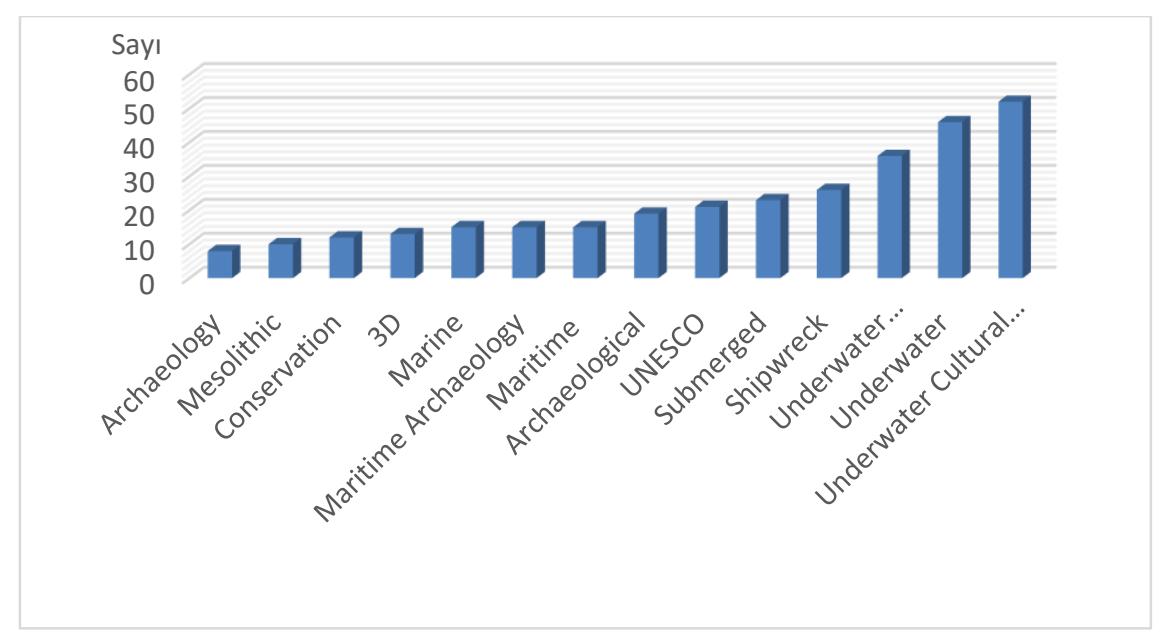

Bu bölümde K.4. kriterinde belirtildiği gibi çalışma kapsamında önceden tespit edilen anahtar kelimeler dışında araştırma makalelerinin özet kısmında olan anahtar kelimeler baz alınmıştır. Analiz kapsamındaki makaleler incelenirken toplamda 931 anahtar kelime kullanıldığ görülmektedir. $\mathrm{Bu}$ anahtar kelimelerden en fazla kullanılan kelimeler ve kelime gruplarının Archaeology, Mesolithic, Conservation, 3D, Marine, Maritime Archaeology, Maritime, Archaeological, UNESCO, Submerged, Shipwreck, Underwater Archaeology, Underwater, Underwater Cultural Heritage olduğu görülmektedir. Sık kullanılan anahtar kelimeler 
arasındaki dağılım yukarıdaki şekilde belirtildiği gibidir (Şekil 4). Yukarıda belirtilen anahtar kelimeler dışında farklı birçok anahtar kelime kullanımı görülmüştür. Bu anahtar kelimelerden bazlları in situ protection, heritage law, photogrammetry, protection, salvage, survey gibi kelime ve kelime gruplarıdır.

\section{K.5. En Çok Yayın Yapan 5 Ülkenin Oransal Dağılımı}

Şekil 5. En Çok Yayın Yapan 5 Ülke

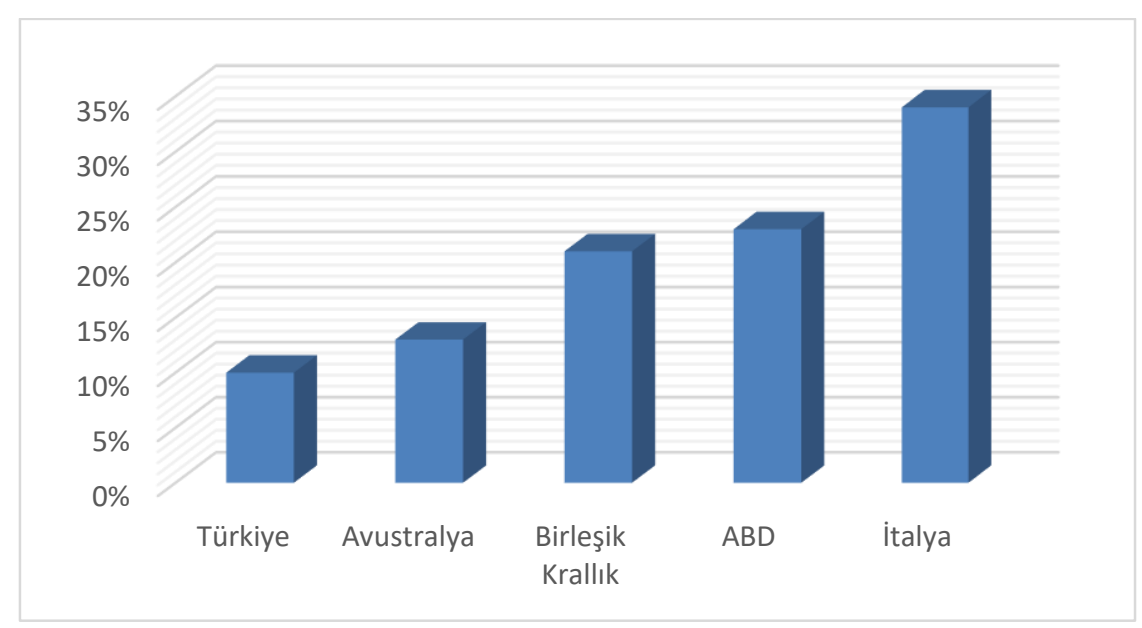

K.5. kriterinde belirtilen en çok yayın yapan ülkeler için yapılan çalışmalar bu bölümde yer almaktadır. Alan hakkında dünyada yapılan çalışmaların hangi ülkelerde yoğunlaştığını görmek açısından önemli bulunmaktadır. Sualtı Kültür Mirası Araştırmaları ile ilgili makalelerin en fazla İtalya' da yayınlandığı görülmektedir. Ardından en fazla yayının ABD'den yapıldığı, sıralamanın devamında Birleşik Krallık, Avustralya ve Türkiye'nin geldiği, ayrıca bu bibliyometrik analiz kapsamında yer alan 250 çalışmanın 38 farklı ülkeden olduğu görülmektedir (Şekil 5).

\section{K.6. Yazarların Uzmanlık Alanlarına Göre Dağılımı}

Şekil 6. Yazarların Uzmanlık Alanlarına Göre Dă̆ılımı

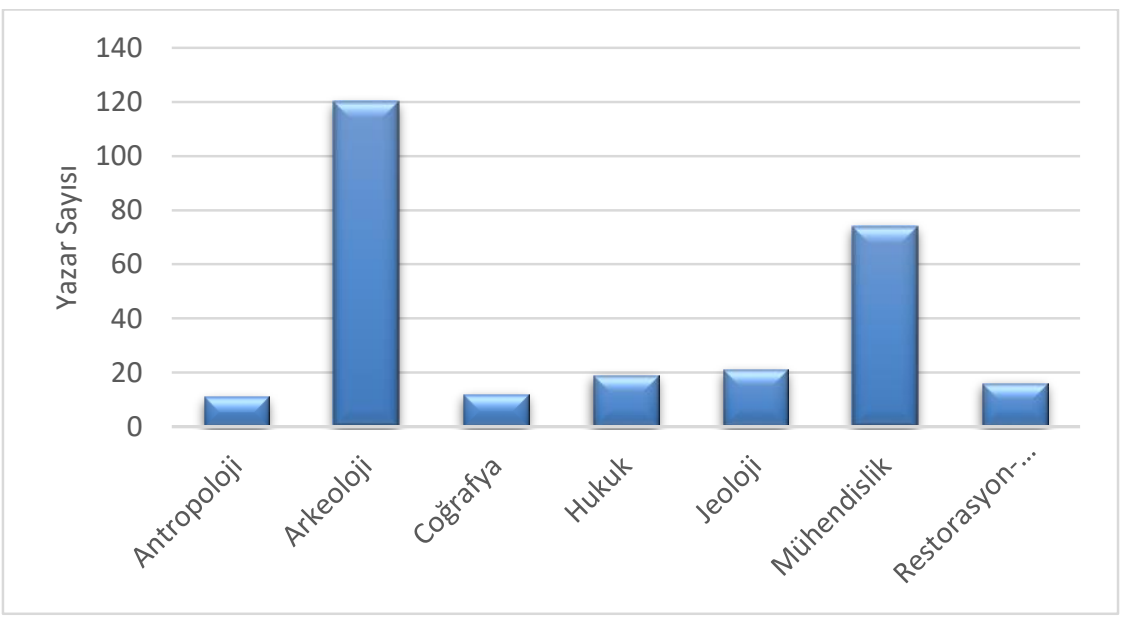

Çalışma kapsamında yer alan K.6. kriterinin gereklilikleri yerine getirilerek yazarların uzmanlık alan bilgilerine ulaşılmıştır. Yazarların uzmanlık alanı bilgileri araştırmaların en fazla hangi alandan araştırmacılar tarafından yapıldığının görülmesi açısından önem arz etmektedir. Yapılan analiz çalışmalarına göre Sualtı Kültür Mirası Araştırmaları alanında çalışma yapmış 
olan yazarların Antropoloji, Arkeoloji, Coğrafya, Hukuk, Jeoloji, Mühendislik ve RestorasyonKonservasyon alanlarından oldukları fakat Arkeoloji (120 yazar) ve Mühendislik (74 yazar) alanındaki uzmanların daha fazla yayın yaptığı görülmektedir (Şekil 6). Şekil 6'da belirtilen uzmanlık alanları dışında analiz çalışması yapılırken çok sayıda olmayan fakat farklı uzmanlık alanlarından da yayın yapan yazarlar bulunmaktadır. Bunlardan bazıları Deniz Sistemleri Tasarımı, Denizcilik Araştırmaları, Mimarlık, Okyanus ve Yer Bilimi, Paleobiyoloji, Uygulamalı Fizik bölümleridir.

\section{K.7. Bu Çalışma Kapsamında “Sualtı Kültür Mirası" Hakkında En Çok Yayın Yapan Dergiler}

Şekil 7. Bu Çalışma Kapsamında "Sualtı Kültür Mirası" Hakkında En Çok Yayın Yapan Dergiler

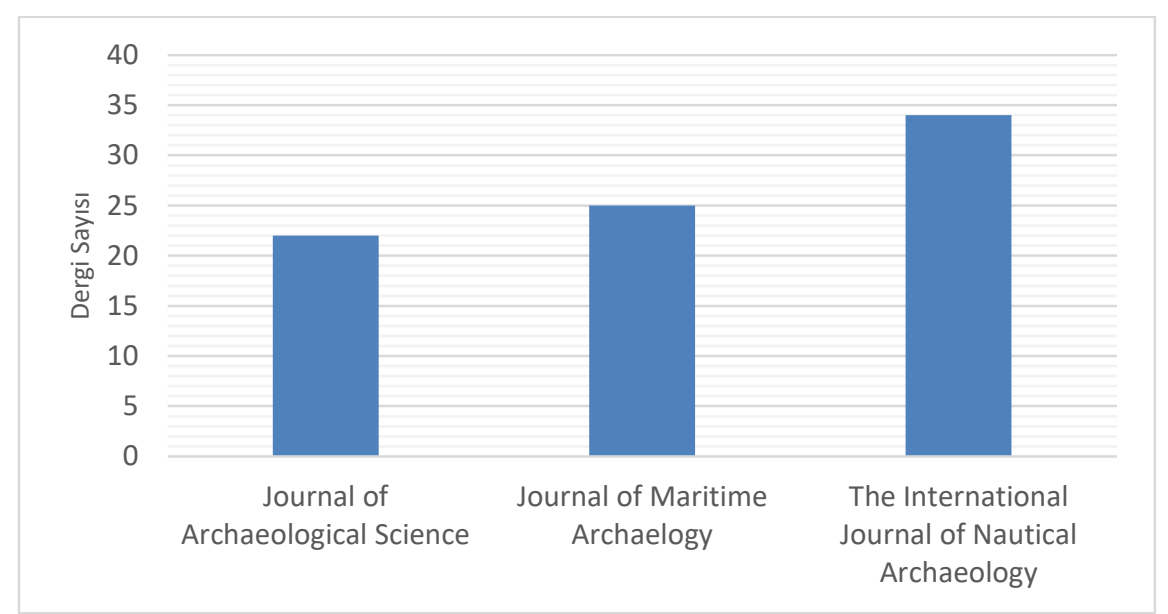

Analiz içerisinde K.7. kriteri incelenen 250 makalenin hangi dergilerde yayınlandığı bilgisini de sunmaktadır. Tüm makalelerin yayınlandığı dergiler incelenip sayısallaştırıldığında Sualtı Kültür Mirası Araştırmaları hakkında çalışan birçok farklı disiplin olmasından dolayı bu alanlara ait farklı disiplinlerin dergileri de karşımıza çıkmaktadır. Fakat yine de ilk üç sırada tamamen arkeoloji alanında yayınlar yapan dergiler yer almaktadır. Sualtı Kültür Mirası Araştırmaları alanında yapılan çalışmaları üzerine en fazla yayın yapan derginin The International Journal of Nautical Archaeology olduğu görülmektedir. İkinci sırada Journal of Maritime Archaeology, üçüncü sırada ise Journal of Archaeological Science bulunmaktadır (Şekil 7).

\section{K.8. Makalelerin Yayınlandığı Dergiler Arasında Arkeolojik Dergilerin Yüzdesel Olarak Payı}

Şekil 8. Makalelerin Yayınlandığı Dergiler Arasında Arkeolojik Dergilerin Yüzdesel Olarak Payı

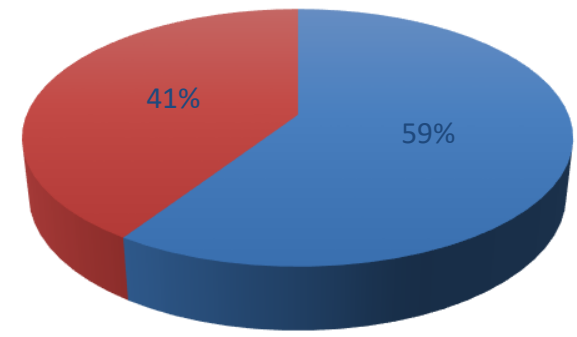

口 Arkeoloji Dergileri $\quad$ Diğer Dergiler 
K.7. kriterinin çalışmaları sırasında elde edilen makalelerin yayınlandığı dergilerin bilgisi ele alınarak sadece arkeolojinin çeşitli alanları hakkında yayın yapan dergilerin diğer disiplinler ile ilgili yayın yapan dergilerden ayırılarak sayısallaştırılması sonucunda K.8. kriterine cevap bulunmuştur. Analiz çerçevesinde incelenen makalelerin yayınlandığı dergilere bakıldığında birçok farklı bilim dalı ile ilgili yayınlar yapan dergiler bulunmaktadır. Çalışma kapsamındaki dergiler incelendiğinde \%41'inin çeşitli alanlarda yayın yapan dergiler olduğu görülmektedir. Bu bilim dergileri Jeoloji, Oşinografi, Coğrafya, Antropoloji, Denizcilik, Kıyı Yönetimi, Ekoloji, Sosyal Bilimler, Kültürel Politika, Uluslararası Hukuk, Bilim ve Teknoloji gibi alanlarda yayınlar yapmaktadırlar. \%59'luk bir payı ise arkeoloji dergileri oluşturmaktadır. Bu pay, içerisinde 1.7. bölümde bahsedilen dergiler gibi Sualtı Arkeolojisi, Deniz Arkeolojisi alanlarında yayın yapan dergileri de kapsamaktadır (Şekil 8).

\section{SONUÇ}

Bir bilim dalında yapılmış olan çalışmalarını seçilen kaynak türü üzerinden inceleme ve alan hakkında yapılan araştırmalar hakkında bilgi edinilmesini, literatürdeki eksikliklerin görülmesini sağlayan bibliyometrik analiz birçok açıdan araştırmacılara yarar sağlamaktadır. Sualtı Kültür Mirası Araştırmaları ile ilgili yapılan bu bibliyometrik analiz çalışmasında ise 6 farklı veri tabanı içerisinde yer alan toplan 250 makalenin yazar, kurum bağlantısı, kullanılan anahtar kelimeler, yayın yılları, alan hakkında yayın yapan dergiler gibi nitelikleri üzerinden incelemeleri yapılmıştır. Bu incelemeler sonucunda en çok makalenin 2016-2020 yılları arasında yayınlandığı görülmüştür. Veri tabanlarında yayınlanan en erken tarihli makalenin 1976 yılında yazılmış olduğu görülmektedir. 2001-2005 yılları arasında çalışma sayılarında bir düşüş görülmektedir. Fakat 2006-2010 yıllarından itibaren sualtı arkeolojisi alanında hem dünya çapında hem de Türkiye'de yapılan kazılar ve bilimsel çalışmalar arttıkça yayınlanan makale sayılarında da bu denli bir artışın görülmesi bir gelişmedir. Bu görülen artış alanda yapılan çalışmaların artması ve araştırmacıların yayın yapması ile doğru orantılı olarak gelişmektedir. Kazı çalışmalarından elde edilen verilerin toplanıp muhafaza edilmesi ya da sergilenmesi kadar, bilimsel bir makale haline dönüştürülüp uluslararası bir paylaşım ağında yayınlanması da önem arz etmektedir. Yayınlanan çalışmaların artması küresel bağlamda gelişimi sağlamakta, aynı zamanda diğer araştırmacılara bir bakış açısı daha yaratarak bilgi paylaşımını arttırmaktadır. $\mathrm{Bu}$ nedenle çalışmaların artışı alanın gelişimi için oldukça büyük bir önem taşımaktadır. Makalelerin \% 42'si tek yazarlı, \% 43'ü 2-4 yazarlı, \%15'i ise 5 ve üstü yazarlıdır. Birden fazla yazarlı çalışmalar genellikle farklı alanlardan bir bakış açısı getirebilecek nitelikte olan yazarlarla yapılmaktadır. Aynı alanda çalışma yürüten yazarlarında birlikte yaptığı çalışmalar bulunmaktadır. Çalışmaların bireysel mi yoksa işbirliği içerisinde birden fazla kişi ile yazılması $\mathrm{m} ı$ daha faydalıdır diye düşünüldügünde yapılan çalışmaya göre bu durum değişebileceği için tartışmaya açık bir konudur. Yazarların \%77'si üniversiteye bağlı olup \%23'ünün üniversite dışı bir kurumdan olduğu görülmektedir. Kuruma bağlı olsun ya da olmasın araştırmacıların tümü alanında uzman kişiler tarafında yapılmaktadır. Üniversitelerde yürütülen akademik çalışmaları destekleyen bir kol da özel kurum ve şirketlerde çalışan araştırmacılardır. Çalışmaların içeriğine göre çeşitli mühendislik ve restorasyon gibi alanlarda çalışan kurumlarla ilişkili araştırmalar da yürütülmektedir. Bu durum Sualtı Kültür Mirası Alanında yapılan çalışmaların sadece akademisyenler tarafından yapılmayıp aynı zamanda diğer kurumlardan da destek alınarak yapıldığını göstermektedir. 
Sualtı arkeolojisi birçok disiplin ile iç içe çalışan bir alandır. Bu yönden makalelerin yazarlarının uzmanlık alanları konusunda da incelemeler yapılmıştır. Yapılan incelemelerde yazarların birçok farklı alanda çalıştıkları görülmektedir. Bu incelemeler sonucunda Arkeoloji (120 yazar) ve Mühendislik (74 yazar) alanlarının ön planda olduğu görülmektedir. Arkeoloji alanında uzmanlığı olan yazarların fazla olması bu çalışma kapsamında normal bir durumdur. Mühendislik alanından yazarın bu denli fazla çalışma sebebi sualtı arkeolojisinin kazı ve araştırma yöntemlerinden kaynaklıdır. Şöyle ki çeşitli mühendislik alanında uzman olan yazarların yapmış olduğu çalışmalar genellikle sualtı araştırma sistemleri üzerine yapılan araştırmalar ve projelerdir. Bu sebeple mühendislik alanından yazarlar da analizin içerisinde 2 . sırada yer edinmiştir. Bunun yanı sıra jeoloji, restorasyon, hukuk, coğrafya, antropoloji alanlarından da yazarların katkılarının azımsanamayacak oranda olduğu söylenebilmektedir. Alanların birbiri ile olan ilişkileri göz önünde bulundurulduğunda ortak çalışmaların artışı alana katkı sağlayacak ve daha geniş bir etki sahası oluşturabilecektir. En fazla kullanılan anahtar kelimeler ve kelime gruplarının Archaeology, Mesolithic, Conservation, 3D, Marine, Maritime Archaeology, Maritime, Archaeological, UNESCO, Submerged, Shipwreck, Underwater Archaeology, Underwater, Underwater Cultural Heritage olduğu belirlenmiştir. En sık kullanılmış olan bu anahtar kelimeler arasında "Mesolithic" dikkat çekmektedir. Örneğin Mesolithic kelimesinin anahtar kelime olarak seçildiği bir makalede yapılan çalışmalardan elde edilen verilerin geçmiş deniz seviyesindeki değişimin kanıtları için incelenmesi ve geçmişteki durumun paleo-coğrafi rekonstrüksiyonlarını üretmek için kullanılması ile yüksek arkeolojik potansiyele sahip on alanın tanımlanmasını kolaylaştırdığ belirtilmiştir (Westley et al., 2011, s. 99). Sualtında kalan tarih öncesi yerleşimlere ait yapılan çalışmalar analiz kapsamında incelenen makaleler içerisinde karşımıza çıkmaktadır. Bu gibi konuları barındıran tarih öncesi çağlar ile ilgili çalışmalarda anahtar kelime olarak mesolithic kullanılmıştır. Mesolithic kelimesinin bulunduğu makaleler incelendiğinde ve karşılaştırmaya gidildiğinde ülkemizde bu konuda bir eksikliğin varlığı da göze çarpmaktadır. Araştırma teknolojilerinin ilerlemesi sayesinde çok daha kapsamlı çalışma olanakları yaratılabilmektedir. Gelişimin sağlanabilmesi açısından bu alandaki incelenip, ülkemizdeki çalışmalara katkılarının olup olamayacağı tartışmalarının yapılmasının faydalı olabileceği düşünülmektedir (Astrup et al., 2020; Benjamin, 2010; Bicket \& Tizzard, 2015; Donahue et al., 2019; Fischer et al., 2007; Hansson et al., 2018; Lodolo \& BenAvraham, 2015; Momber, 2000; Skriver et al., 2018; Vos et al., 2015; Ward et al., 2019; Westley, 2015; Westley et al., 2011). Analiz içerisinde belirtilen anahtar kelimeler yapılan araştırmaların çeşitliliğini göz önüne sermektedir. Alanda yapılan önemli çalışmalardan biride konservasyon çalışmalarıdır. Bu sebeple “conservation" kelimesinin de sıkça kullanıldığı ve bu konuda çalışmaların sayıca öne çıktığı görülmektedir.

Sualtı Kültür Mirası Araştırmaları ile ilgili yayınlanan makaleler incelendiğinde en fazla yayını 137 makale ile İtalya'nın yaptığı görülmektedir. İtalya antik çağlardan itibaren tarihsel önemini korumuştur. Bu yarımada da sualtı araştırmalarının yapılabileceği arkeolojik alanların olma potansiyelinin yüksek olduğu öngörülebilmektedir. Tüm makalelerin yayınlandığ 1 dergiler incelendiğinde bu alanda öne çıkan ve Sualtı Kültür Mirası Araştırmaları alanındaki makalelerin en fazla yayınlandığ 1 dergilerde birinci sırada The International Journal of Nautical Archaeology ikinci sırada Journal of Maritime Archaeology, üçüncü sırada ise Journal of Archaeological Science bulunmaktadır. Üç dergiden The International Journal of Nautical Archaeology dergisi deniz arkeolojisinin tüm yönleriyle ilgili daha fazla araştırma yapmak ve sonuçların yayınlanmasını sağlamak amacıyla 1981 yılında kurulmuştur ve IJNA, deniz arkeolojisinin tüm 
yönleriyle ilgili fikir alışverişi ve araştırma için bir forum olarak bulunmaktadır (Maritime Archaeology, 2020). Journal of Maritime Archaeology deniz arkeolojisinin hem karada hem de su altında tüm yönlerini ele alan ilk uluslararası dergidir. Siteler, teknoloji, peyzaj, yapı ve miras yönetimi konuları ile ilgili teori, uygulama ve analizi kapsamaktadır. Dergi, arkeoloji ve kültürel coğrafya, tarih, etnografi, oşinografi ve antropoloji gibi disiplinlere uzanan denizcilik yaklaşımları için bir kanal sunmaktadır (Springer, 2020). Journal of Archaeological Science dergisinin ise geniş arkeolojik öneme sahip odak makaleleri, orijinal araştırma makaleleri ve önemli derleme makaleleri yayınlamaktadır. Dergi, arkeolojik araştırmalardan elde edilen bilimsel bilgilerin kalitesini ve güvenilirliğini artırarak büyük tartışmaları bilgilendirmek için bilimsel yöntemler geliştirmek ve uygulamak konusunda ortak bir ilgiyi paylaşan, çok farklı bilimsel geçmişlere sahip arkeologlar ve bilim adamları için uluslararası bir forum sunmaktadır (Elsevier, 2020). Dergilerin içerikleri araştırıldığında ise bu analiz kapsamındaki makalelerin yayınlandığı dergilerin \% 59'unun arkeoloji dergisi \% 41'inin ise diğer bilimsel alanlar ile ilgili yayınlar yapan dergiler olduğu görülmektedir.

Multidisipliner çalışmanın bilimsel açıdan ne kadar yarar sağladığı ve bakış açısı geliştirdiği her alanda bilinmektedir. Analiz içerisinde yapılan tüm değerlendirmeler bir noktada bu konuyu da işaret etmektedir. Sualtı Kültür Mirası Araştırmalarında farklı disiplinler ile çalışmanın yürütülen araştırmaların seyrini değisstirebileceği görülmektedir. Çeşitli mühendislik alanları, restorasyon-konservasyon, biyoloji gibi bir çok disiplinin varlığı, sualtı kültür miraslarının araştırılmasında katkıları arttıkça, alanın gelişiminin hızlanmasını sağladığı görülmektedir (Capra et al., 2015; Davidde, 2002; Ruffolo et al., 2017). Sualtı Kültür Mirası Araştırmalarının gelişiminin ülkelere hem bilimsel hem de ekonomik açıdan katkıları bulunmaktadır. Örneğin, ekonomide önemli rol oynayan turizmi büyük ölçüde desteklemekte ve küresel çapta bir etkileşim oluşturmaktadır. Bu bağlamda Sualtı Kültür Mirası Araştırmalarının gelişimi bölgelerin ekonomik kalkınmasına da fayda sağlamaktadır. Aynı zamanda Türkiye'nin üç tarafı denizlerle çevrili ve antik çağda da önemli bir stratejik konuma sahip olduğu konusu düşünüldüğünde sualtı kültür mirası açısından ne derece zengin olduğu tahmin edilebilmektedir. Bu yoğun kültür varlıklarının araştırılmasında görev alacak araştırmacıların nitelikli birer bilim insanı olarak yetiştirilmesi için özellikle kıyı şeridinde spesifik noktalarda bulunan üniversitelerimizde anabilim dallarının ve ya bölümlerin açılmasının Sualtı Kültür Mirası Araştırmalarına oldukça katkı sağlayacağı düşünülmektedir.

\section{KAYNAKÇA}

Al, U. (2008). Türkiye'nin bilimsel yayın politikası: Atıf dizinlerine dayalı bibliyometrik bir yaklaşım. Yayınlanmamış doktora tezi, Hacettepe Üniversitesi, Ankara.

Allotta, B., Baines, S., Bartolini, F., Bellavia, F., Colombo, C., Conti, R., Costanzi, R., Dede, C., Fanfani, M., Gelli, J., Gundogdu, H. T., Monni, N., Moroni, D., Natalini, M., Pascali, M. A., Pazzaglia, F., Pugi, L., Ridolfi, A., Reggiannini, M., ... Tekdemir, E. I. (2015). Design of a modular Autonomous Underwater Vehicle for archaeological investigations. MTS/IEEE OCEANS 2015 - Discovering Sustainable Ocean Energy for a New World, Genova. https://doi.org/10.1109/OCEANS-Genova.2015.7271398

Astrup, P. M., Skriver, C., Benjamin, J., Stankiewicz, F., Ward, I., McCarthy, J., Ross, P., Baggaley, P., Ulm, S., \& Bailey, G. (2020). Underwater shell middens: Excavation and remote sensing 
of a submerged mesolithic site at Hjarnø, Denmark. Journal of Island and Coastal Archaeology, 15(4), 457-476.

Aygün Özkan, Ç. (2019). Elazı̆̆ Hazar Gölü Orta Çağ batık yerleşimi arkeolojik araştırması sonuçları. Akdeniz Sanat, 13, 215-226.

Benjamin, J. (2010). Submerged prehistoric landscapes and underwater site discovery: Reevaluating the "Danish Model" for international practice. Journal of Island and Coastal Archaeology, 5(2), 253-270.

Bicket, A., \& Tizzard, L. (2015). A review of the submerged prehistory and palaeolandscapes of the British Isles. Proceedings of the Geologists' Association, 126(6), 643-663.

Blot, J. Y. (1996). Underwater archaeology: Exploring the world beneath the sea. UK: Gardners Books.

Bowen, G. A. (2009). Document analysis as a qualitative research method. Qualitative Research Journal, 9(2): 27-40.

Bruno, F., Barbieri, L., Muzzupappa, M., Tusa, S., Fresina, A., Oliveri, F., Lagudi, A., Cozza, A., \& Peluso, R. (2019). Enhancing learning and access to Underwater Cultural Heritage through digital technologies: the case study of the "Cala Minnola" shipwreck site. Digital Applications in Archaeology and Cultural Heritage. 10 Haziran 2020 tarihinde https://doi.org/10.1016/j.daach.2019.e00103 adresinden erişildi.

Capra, A., Dubbini, M., Bertacchini, E., Castagnetti, C., \& Mancini, F. (2015). 3D reconstruction of an underwater archaelogical site: Comparison between low cost cameras. International Archives of the Photogrammetry, Remote Sensing and Spatial Information Sciences - ISPRS Archives, 40(5W5), 67-72.

Davidde, B. (2002). Underwater archaeological parks: A new perspective and a challenge for conservation - The Italian panorama. International Journal of Nautical Archaeology, 31(1), 8388.

Donahue, R. E., Fischer, A., Burroni, D. B., Malm, T., \& Johansen, M. (2019). Microwear analysis aiding excavation prioritization at the submerged Mesolithic settlement of Orehoved, Denmark. Journal of Archaeological Science: Reports, 23(November 2018), 540-548.

Fischer, A., Richards, M., Olsen, J., Robinson, D. E., Bennike, P., Kubiak-Martens, L., \& Heinemeier, J. (2007). The composition of mesolithic food: Evidence from the submerged settlement on the Argus Bank, Denmark. Acta Archaeologica, 78(2), 163-178.

Gölbaş, A. (2019). Sualtı arkeolojisinin terminoloji sorunsalı. Cedrus, 7(1), 581-605.

Hansson, A., Nilsson, B., Sjöström, A., Björck, S. Holmgren, S., Linderson, H. Magnell, O., Rundgren, M., \& Hammarlund, D. (2018). A submerged Mesolithic lagoonal landscape in the Baltic Sea, south-eastern Sweden - Early Holocene environmental reconstruction and shore-level displacement based on a multiproxy approach. Quaternary International, 463, 110-123.

Hotamışlı, M. \& Efe, D. (2005). Duygusal zeka ve liderlik ilişkisi bağlamındaki çalışmaların bibliyometrik analiz ile incelenmesi. Çukurova Üniversitesi İ̈BF Dergisi, 19(1), 101-121.

https://www.springer.com/journal/11457. 15 Mayıs 2020 tarihinde erişildi. 
https://www.journals.elsevier.com/journal-of-archaeological-science/ 15 Mayis 2020 tarihinde erişildi.

http://www.maritimearchaeology.com/information/journals/ijna/ 15 Mayss 2020 tarihinde erişildi.

http://tusside.tubitak.gov.tr/tr/yontemlerimiz/VeriToplama?country_id=mailto:tusside\%40tubi tak.gov.tr 15 Mayıs 2020 tarihinde erişildi.

ICOMOS (1990). Arkeolojik Mirasın Korunması ve Yönetimi Tüzüğü (Z. Ahunbay, Çev.). 10 Haziran 2020 tarihinde https://dergipark.org.tr/tr/download/issue-file/23399 adresinden erişildi.

Jaklič, A., Erič, M., Mihajlović, I., Stopinšek, Ž., \& Solina, F. (2015). Volumetric models from 3D point clouds: The case study of sarcophagi cargo from a 2nd/3rd century AD Roman shipwreck near Sutivan on island Brač, Croatia. Journal of Archaeological Science, 62, 143152.

Jing, Y., \& Li, J. (2019). Who owns underwater cultural heritage in the South China Sea. Coastal Management, 47(1), 107-126.

Lin, Z. (2020). The protection of sunken WWII warships located in Indonesian or Malaysian territorial waters. Marine Policy, 113. 10 Aralık 2020 tarihinde https://doi.org/10.1016/j.marpol.2019.103804 adresinden erişildi.

Lodolo, E., \& Ben-Avraham, Z. (2015). A submerged monolith in the Sicilian Channel (central Mediterranean Sea): Evidence for Mesolithic human activity. Journal of Archaeological Science: Reports, 3, 398-407.

Lu, B., \& Zhou, S. (2016). China's state-led working model on protection of underwater cultural heritage: Practice, challenges, and possible solutions. Marine Policy. 1 Aralık 2020 tarihinde https://doi.org/10.1016/j.marpol.2015.12.003 adresinden erişildi.

Momber, G. (2000). Drowned and deserted: A submerged prehistoric landscape in the Solent, England. International Journal of Nautical Archaeology, 29(1), 86-99.

Nornes, S. M., Ludvigsen, M., Ødegård, Ø., \& Sørensen, A. J. (2015). Underwater photogrammetric mapping of an intact standing steel wreck with ROV. IFAC-

Nornes, S. M., Ludvigsen, M., Ødegård, Ø., \& Sørensen, A. J. (2015). Underwater photogrammetric mapping of an intact standing steel wreck with ROV. IFACPapersOnLine. 1 Aralı 2020 tarihinde https://doi.org/10.1016/j.ifacol.2015.06.034 adresinden erişildi.

Öniz, H.; Karademir, M. (2018). Antalya ve Mersin İli kıyıları sualtı araştırmaları 2016. AMİSOS, $3(4), 152-166$.

Öniz, H. (2019). A new Bronze Age shipwreck with ingots in the west of Antalya-preliminary results. Palestine Exploration Quarterly. 1 Aralı 2020 tarihinde https://doi.org/10.1080/00310328.2019.1579467 adresinden erişildi.

Özdoğan, M. (2011). 50 soruda arkeoloji. İstanbul: Bilim ve Gelecek Kitaplığı. 
Richards, V., MacLeod, I., \& Veth, P. (2016). The Australian historic shipwreck preservation project: In situ preservation and long-term monitoring of the clarence (1850) and James Matthews (1841) shipwreck sites. Conservation and Management of Archaeological Sites. 1 Aralık 2020 tarihinde https://doi.org/10.1080/13505033.2016.1182759 adresinden erişildi.

Ruffolo, S. A., Ricca, M., Macchia, A., \& La Russa, M. F. (2017). Antifouling coatings for underwater archaeological stone materials. Progress in Organic Coatings, 104, 64-71.

Skriver, C., Astrup, P. M., \& Borup, P. (2018). Hjarnø Sund - all year, all inclusive. A submerged Late Mesolithic coastal site with organic remains. Danish Journal of Archaeology, 7(2), 195217.

Tuğcu, İ. (2017). Liman Tepe / Klazomenai antik limanı doğu mendireği çalışmaları. Çukurova Üniversitesi Sosyal Bilimler Enstitüsü Dergisi, 26(1), 85-101.

Underwood, C. J., \& Manders, M. (2019). Building knowledge and connections: The success of the UNESCO international capacity building training programmes for cultural heritage management of underwater archaeological sites. Journal of Maritime Archaeology. 1 Aralık 2020 tarihinde https://doi.org/10.1007/s11457-019-09237-w adresinden erişildi.

UNESCO (2001). Convention on the protection of underwater cultural heritage. Fransa: UNESCO.

UNESCO Info kit. (2018). Convention on the protection of underwater cultural heritage. Fransa: UNESCO.

Vos, P. C., Bunnik, F. P. M., Cohen, K. M., \& Cremer, H. (2015). A staged geogenetic approach to underwater archaeological prospection in the Port of Rotterdam (Yangtzehaven, Maasvlakte, The Netherlands): A geological and palaeoenvironmental case study for local mapping of Mesolithic lowland landscapes. Quaternary International, 367, 4-31.

Yağc1, R.-Yiğitpaşa, D. (2018). Soli Pompeiopolis kazıları 2017. ANMED ANADOLU AKDENİŻ Arkeoloji Haberleri, 16, 123-131.

Ward, I., Moe-Astrup, P., \& Merigot, K. (2019). At the water's edge: Micromorphological and quantitative mineral analysis of a submerged Mesolithic shell midden at Hjarnø Sund, Denmark. Journal of Archaeological Science, 102(December 2018), 11-25.

Westley, K. (2015). Submerged Mesolithic landscape investigation, Eleven Ballyboes, Republic of Ireland. International Journal of Nautical Archaeology, 44(2), 243-257.

Westley, K., Quinn, R., Forsythe, W., Plets, R., Bell, T., Benetti, S., McGrath, F., \& Robinson, R. (2011). Mapping submerged landscapes using multibeam bathymetric data: A case study from the north coast of Ireland. International Journal of Nautical Archaeology, 40(1), 99-112. 